\title{
Tako-Tsubo Cardiomyopathy Triggered by Paroxysmal Supraventricular Tachycardia in an Octogenarian
}

\author{
M. Hartmann - G. K. van Houwelingen - \\ H. P. C. M. Lambregts • P. M. J. Verhorst • \\ C. von Birgelen
}

Published online: 16 December 2010

(C) The Author(s) 2010. This article is published with open access at Springerlink.com

An 82-year-old emotionally stressed woman was admitted with palpitations and chest pain. Her blood pressure was $95 / 60 \mathrm{mmHg}$ and heart rate $150 \mathrm{beats} / \mathrm{min}$. The electrocardiogram (ECG) showed a regular small QRS-complex tachycardia (Fig. 1a). Serum levels of creatinine $(220 \mu \mathrm{mol} / \mathrm{l})$ and troponin I $(0.12 \mu \mathrm{g} / \mathrm{l})$ were elevated. Intravenous adenosine ( $6 \mathrm{mg}$ bolus) terminated the tachycardia. After conversion, the ECG showed sinus rhythm with slow precordial R-wave progression (Fig. 1b). The blood pressure returned to normal, and her chest discomfort disappeared. Transthoracic echocardiography showed akinesia/dyskinesia of the mid-apical left ventricular segments, hyperkinesia of the basal segments, and moderately depressed systolic function (Fig. 2a-b). The clinical picture was interpreted as potentially ischaemic. One day later, the

\footnotetext{
M. Hartmann $(\bowtie) \cdot$ G. K. van Houwelingen •

H. P. C. M. Lambregts - P. M. J. Verhorst - C. von Birgelen

Department of Cardiology, Thoraxcentrum Twente,

Medisch Spectrum Twente,

Haaksbergerstraat 55 ,

7513ER, Enschede, the Netherlands

e-mail: m.hartmann@mst.nl

C. von Birgelen

MIRA Institute for Biomedical Technology and Technical

Medicine, University of Twente,

Enschede, the Netherlands
}

chest pain briefly recurred, the ECG showed QT prolongation with negative $\mathrm{T}$ waves (Fig. 1c), and coronary angiography (Fig. 1d) revealed no significant stenosis. The patient remained symptom free, troponin levels decreased, and the ECG normalised. Echocardiography on day 5 revealed a fully restored left ventricular function (Fig. 2c-d). The clinical picture was finally interpreted as Tako-Tsubo cardiomyopathy (TTCMP) triggered by paroxysmal supraventricular tachycardia.

TTCMP is characterised by severe transient systolic dysfunction of apical and/or mid left ventricular segments, mimicking myocardial infarction in the absence of coronary stenoses. Catecholamine excess may lead to left ventricular dysfunction as a result of microvascular spasm or direct catecholamine-mediated effects on cardiomyocytes [1]. TTCMP is triggered by emotional and/or physical stress, predominantly in elderly women [2]. ECG abnormalities include ST-segment elevation or T-wave inversions with QT-interval prolongation [1-4]. Elevation of cardiac biomarkers is typically mild while left ventricular compromise is significant but generally recovers within 1-4 weeks [1-3]. The current case includes interesting and unique aspects. Firstly, the patient is much older than most patients with TTCMP [1-3]. In addition, a regular supraventricular tachycardia as trigger of TTCMP has not been described before. The sudden onset of palpitations may have caused emotional distress with elevated catecholamine levels triggering TTCMP [1]. 

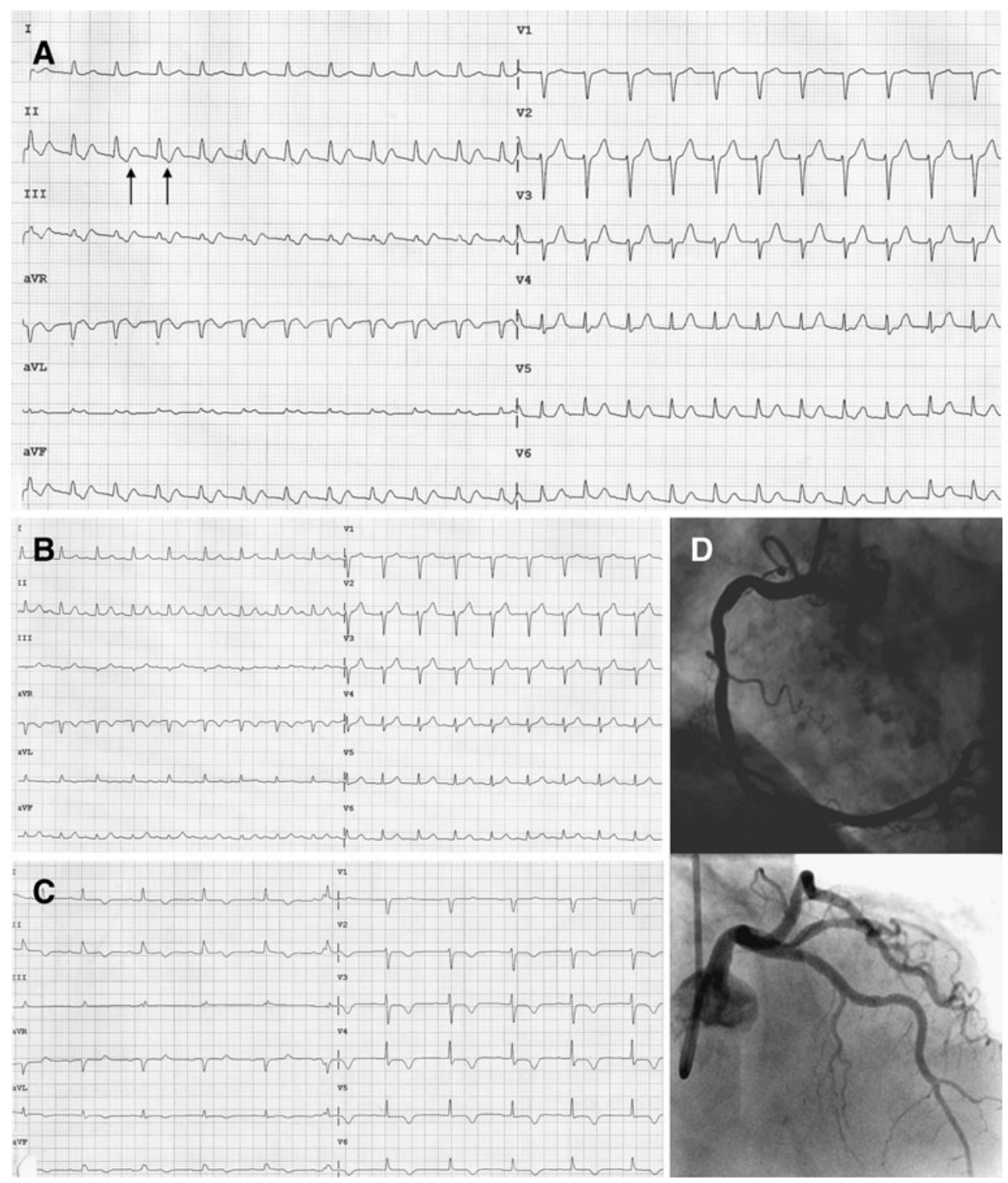

Fig. 1 a ECG at admission revealed a regular small QRS-complex tachycardia with retrograde $\mathrm{P}$ waves after the QRS complex (circus movement via a concealed bypass or AV-nodal re-entry tachycardia) (arrows). b ECG after conversion showed sinus rhythm with slow R progression in the precordial leads without changes of the ST-T segments or signs of pre-excitation. c ECG with sinus rhythm and negative $\mathrm{T}$ waves with QT prolongation after brief episode of recurrent chest discomfort. d Coronary angiography showed no significant stenosis and normal flow 


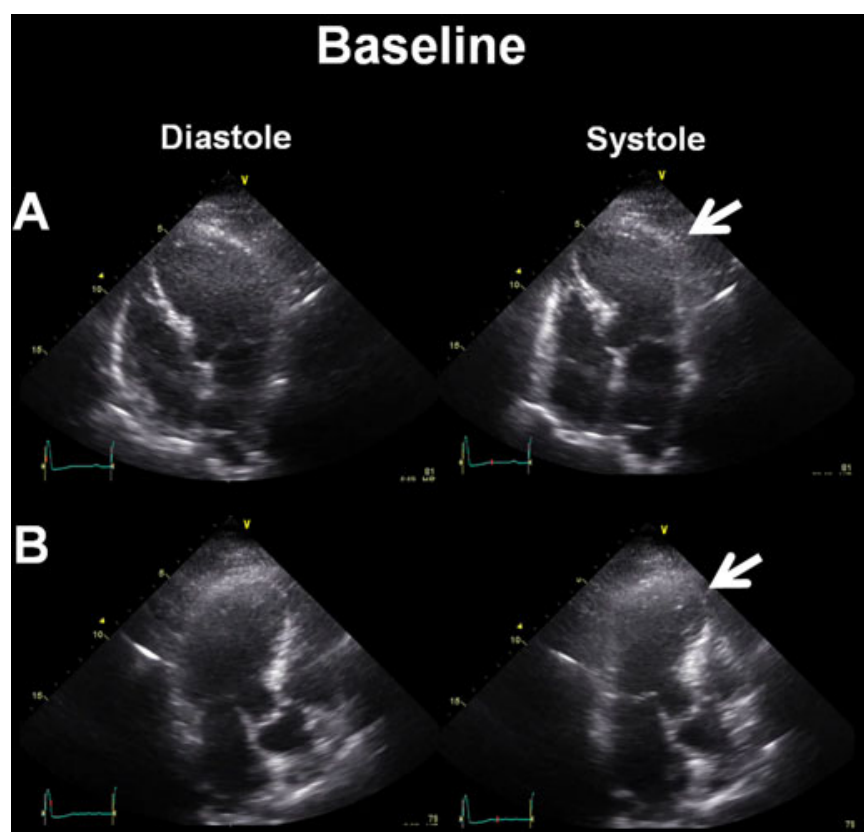

Fig. 2 Echocardiogram at admission revealed akinesia/dyskinesia of the mid-apical left ventricular segments (arrows) with hyperkinesia of the basal segments and moderately depressed global systolic left

Open Access This article is distributed under the terms of the Creative Commons Attribution Noncommercial License which permits any noncommercial use, distribution, and reproduction in any medium, provided the original author(s) and source are credited.

\section{References}

1. Akashi YJ, Goldstein DS, Barbaro G, Ueyama T. Takotsubo cardiomyopathy: a new form of acute, reversible heart failure. Circulation. 2008;118:2754-62.

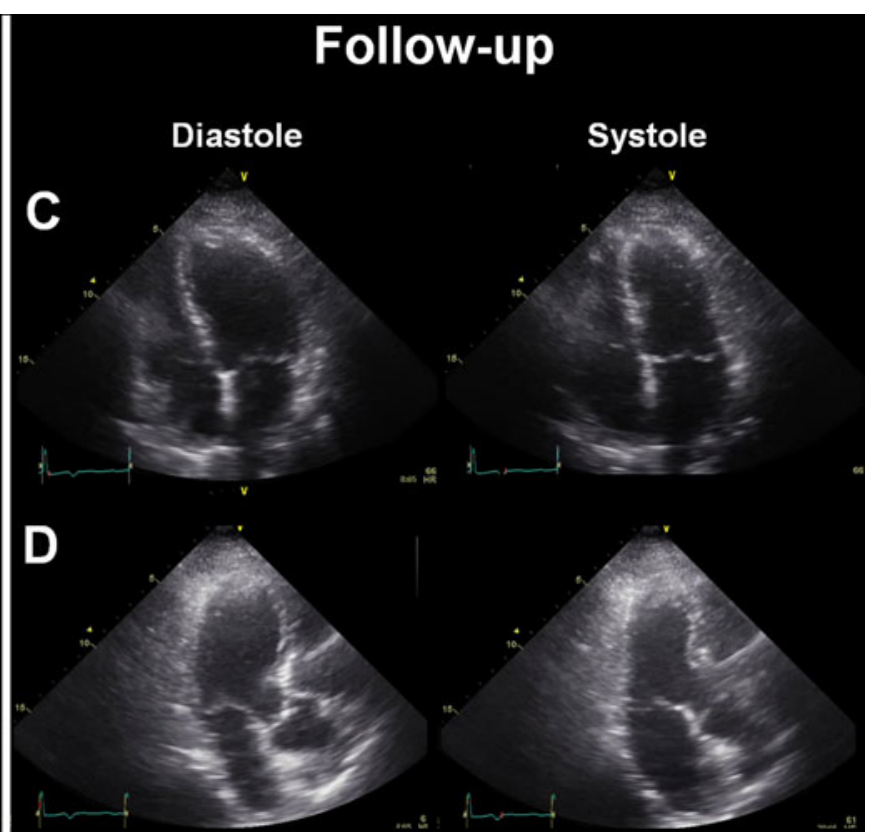

ventricular function ( $a$ four-chamber view, $b$ apical five-chamber view). Echocardiogram on day 5 ( $c$ four-chamber view, $d$ apical fivechamber view right) showed normal left ventricular function
2. Gianni M, Dentali F, Grandi AM, Sumner G, Hiralal R, Lonn E. Apical ballooning syndrome or takotsubo cardiomyopathy: a systematic review. Eur Heart J. 2006;27:1523-9.

3. Tsuchihashi K, Ueshima K, Uchida T, Oh-mura N, Kimura K, Owa $\mathrm{M}$, et al. Transient left ventricular apical ballooning without coronary artery stenosis: a novel heart syndrome mimicking acute myocardial infarction. J Am Coll Cardiol. 2001;38:11-8.

4. Mahida S, Dalageorgou C, Behr ER. Long-QT syndrome and torsades de pointes in a patient with Takotsubo cardiomyopathy: an unusual case. Europace. 2009;11:376-8. 